\title{
A defesa da vida ativa em Mestre Eckhart
}

\section{The defense of the active life in Meister Eckhart}

\author{
SAULO MATIAS DOURADO ${ }^{28}$
}

Resumo: Há, na filosofia medieval, um debate sobre a prioridade da vida ativa ou da vida contemplativa no caminho da perfeição do homem. Existe em Tomás de Aquino e, em Santo Agostinho, ponderações sobre a necessidade de ambos, mas uma preferência pela contemplação. Mestre Eckhart, a partir da parábola de Marta e Maria, propõe uma interpretação diferente sobre a compreensão de atividade e coloca Marta como paradigma, porque não apenas une-se à divindade em seu ser, como a frutifica em seu afazer. Eckhart nomeia tal estado supremo da alma como "mulher", isto é, fecundo por princípio, capaz de engendrar em todas as obras a centelha divina.

Palavras-chave: Mestre Eckhart. Vida ativa. Desprendimento. Mística.

Abstract: In medieval philosophy, there is a debate on the priority of the active life or the contemplative life in man's perfections. It exists in Thomas Aquinas and St. Augustine weights on the need for both, but a preference for contemplation. Meister Eckhart, from the parable of Martha and Mary, proposes a different interpretation of the understanding of activity. He places Marta as a paradigm, because not only joins the divinity within your being, as the fruits on your to-do. Eckhart names such supreme state of the soul as "woman", that is , fecund in principle, able to engender in all the work the divine spark.

Keywords: Meister Eckhart. Active life. Detachment. Mystic.

${ }^{28}$ Licenciado e Mestre em Filosofia pela UFBA. É professor em escolas privadas de Salvador. Foi bolsista do PET entre 2009 e 2010, no Curso de Filosofia da UFBA. O presente artigo resulta do terceiro capítulo de sua dissertação, defendido em março de 2015, sob orientação da Profe. Drà. Nancy Mangabeira Unger. 
Do seguinte modo se conta a parábola de Marta e Maria:

Estando em viagem, entrou num povoado, e certa mulher, chamada Marta, recebeu-o em sua casa. Sua irmã, chamada Maria, ficou sentada aos pés do Senhor, escutando-lhe a palavra. Marta estava ocupada pelo muito serviço. Parando, por fim, disse: "Senhor, a ti não importa que minha irmã me deixe assim sozinha a fazer o serviço? Dize-lhe, pois, que me ajude". O Senhor, porém, respondeu: "Marta, Marta, tu te inquietas e te agitas por muitas coisas; no entanto, pouca coisa é necessária, até mesmo uma só. Maria, com efeito, escolheu a melhor parte, que não lhe será tirada" (BÍBLIA, 1982, Lc, 10, 38).

A interpretação mais corrente para esta passagem é a que parece à primeira vista: Jesus repreenderia Marta por ocupar-se de tarefas mundanas e não estar, qual Maria, concentrada na ausculta das palavras sagradas. O desfecho da parábola traz textualmente que Maria escolheu a melhor parte, a de estar aos pés do manto, em vez de atarefar-se em coisas mundanas e, talvez, distrair-se. Segundo Tanquerey, se a palavra contemplação não aparece nas Escrituras, a sua "realidade é claramente descrita" (TANQUEREY, 1955, p. 54) na parábola pela figura de Maria, o que fortalece a aceitação da superioridade de Maria, porque remonta à tradição da vita contemplativa e da vita activa, em que se tomou a contemplação como a via própria do conhecimento de Deus, simbolizada por Maria, em detrimento da atividade de Marta.

Para ficar clara a distinção entre tais conceitos, tão debatidos na filosofia dos pensadores medievais, podemos recorrer à doutrina de Agostinho. No IV artigo do opúsculo De Magistro, o filósofo se propõe a discutir "se ensinar é ato da vida contemplativa ou ativa" 
(AGOSTINHO, 1987, p. 45). Desse modo, o ensino e a pregação, a transmissão daquilo que se contemplou passará a fazer parte da vida contemplativa, e este se tomaria como um ideal geral. Na contemplação, se é movido a deixar "a Deus por Deus". A vida ativa, nesta concepção, tampouco seria algo oposto e negativo: é a ordenação para o bem do próximo, do outro homem. Contudo, a completude rumo à perfeição será pela contemplação, a fim de se chegar à verdade suprema. O ideal de perfeição se baseia na contemplação, sem deixar de reconhecer a ação como necessária, uma vez que o homem não é só espírito. Tomás de Aquino, na Suma Teológica, assim pontua, em referência a Agostinho:

Às vezes, premidos pelas necessidades, temos de deixar a contemplação para nos darmos às obras da vida ativa; mas não de modo que devamos abandonar completamente a contemplação. Por isso, diz Agostinho: $O$ amor da verdade deseja um santo repouso. Mas, a caridade, se for preciso, faz-nos aceitar um justo trabalho, isto é, o da vida ativa. Se ninguém, contudo, nos impuser essa carga entreguemo-nos ao estudo e à contemplação da verdade. Mas, sendo-nos ela imposta, a caridade mesmo nos impõe a necessidade de aceitá-la. Nem por isso, contudo, devemos abandonar de todo a doce contemplação da verdade, não seja que, privados dessa suavidade, sintamos a opressão da necessidade. Por onde é claro que quem é chamado da vida contemplativa para a ativa, não sofre uma subtração, mas deve fazer antes uma adição (AQUINO, 2006, p. $581)$.

Não há, pois, uma dicotomia, grosso modo, entre vida contemplativa e vida ativa em que uma é sumamente boa e a outra reprovável, pois. A partir do exemplo da caridade, que é a virtude da 
doação de si para o outro, expõe-se que a necessidade pressiona o homem a agir. $\mathrm{O}$ homem não deve recear que a sua contemplação se esvaia ao agir. Aí há uma indicação de que esta contemplação se torne um bem a ser preservado para além das necessidades. Existe, pois, uma escolha por qual seria "a melhor parte", isto é, a que mais uniria o homem ao divino. Esta caberia à contemplação, por conter a ciência da salvação, para além do terreno e do tempo, tal como Aquino menciona pelo nome de Maria, interpretando a parábola referida.

'No princípio era o Verbo' a quem Maria ouvia. 'O Verbo se fez carne' a quem Marta servia. [...] Escolham para si a melhor parte, isto é, da vida contemplativa; exerçam a palavra, abeberem-se da doce doutrina, cultivem a ciência da salvação... (Marta), tu não escolheste algo de mal, entretanto, (Maria) escolheu a melhor (AQUINO, 2006, p. 598).

No trecho anterior, Tomás de Aquino compara o princípio enquanto Verbo a Maria, e o Verbo enquanto carne a Marta. São dois modos da mesma dimensão maior que é o Verbo. Marta não deixa de ser verbo ao ser carne, tampouco Maria, puro Verbo, paira solitária. São dinâmicas, tal como a Trindade, que é, a um só tempo, pai, filho e espírito santo (cf. SCHUBACK, 20oo, p. 67). Também Marta não pode ser desconsiderada, pois o próprio Verbo também se fez Carne. Assim, Tomás cita mais uma vez Agostinho, em um dos sermões nos quais o pensador do século $V$ comenta o provérbio de Marta e Maria: a "doce doutrina" e "a ciência da salvação" são expressões que aparecem no Sermão 103 de Agostinho, dedicado à interpretação da passagem do Evangelho de Lucas.

Agostinho demonstra, com mais ênfase, que Maria não poderia ser vista sem Marta. Para tanto, faz uma redução ao absurdo, 
clamando que se deixe de "visitar os enfermos" ou "enterrar os mortos", já que os homens deveriam apenas ocupar-se com a contemplação. Contemplar é a "ciência da salvação", "a doçura da doutrina", porém não pode ser vista em separado, assim como tampouco se podem considerar as atividades materiais e temporais sem uma relação com a transcendência e as causas espirituais. Desse modo, observa Agostinho:

Devemos pensar que Jesus vituperou a atividade de Marta, ocupada no exercício da hospitalidade, ao recebê-lo em sua casa? Como podia ser com justiça censurada quem se deleitava em acolher tão notável Hóspede? Se assim for, cessem os homens de socorrer os necessitados e escolham para si a melhor parte, a qual não lhes será tirada; dediquem-se à meditação da palavra divina, almejem ardentemente a doçura da doutrina, consagrem-se à ciência da salvação; não se preocupem em saber se há na aldeia algum peregrino ou algum pobre sem alimento ou roupa; desinteressem-se de visitar os enfermos, de resgatar o cativo, de enterrar os mortos; abandonem as obras de misericórdia e apliquem-se à única ciência. Se esta é a melhor parte, por que não nos dedicarmos todos a ela, já que, nessa matéria, temos o próprio Senhor como nosso defensor? (AGOSTINHO, 1986, p. 1073).

A questão de Agostinho se torna também a de Eckhart: se Marta é uma dimensão necessária para a perfeição, por que Jesus teria indicado Maria ao dizer que esta escolheu a "melhor parte"? De que modo não seria tão obviamente uma defesa plena da vita contemplativa sobre a vita ativa, a ponto de Marta estar na "pior parte"? Caminhos de Agostinho e Tomás de Aquino para responder a questão da parábola de Marta e Maria são vastos e requereriam uma 
empreitada por si só. Com a proposta colocada por Mestre Eckhart, podemos seguir sem descrever em detalhes o quanto se diferencia ou se assemelha aos outros autores medievais, mas, sim, que é uma resposta a esta tradição e que é considerada até hoje, no interior da teologia, como uma das mais distintas interpretações (JARCZYK ET LABARRIERE, 1999, p. 215). Aqui, nós a consideraremos em seu sentido filosófico, pontuando o sentido de estar presente nas figuras de Marta e de Maria, bem como a predileção de Marta. Trata-se, aqui, de um aspecto que nem Tomás de Aquino, nem Agostinho, foram tão explícitos.

No Sermão 86, traduzido como "A excelência de Marta sobre Maria", Eckhart começa por enumerar os motivos que fizeram Maria sentar-se aos pés de Jesus: 1) "a sua alma estava tomada pela bondade de Deus"; 2) um desejo indizível, de ansiar e não saber por que, de querer e não saber o quê; e 3) o doce consolo por haurir as palavras eternas. Em contrapartida, também traz três razões para Marta agir como agia, na ocupação de atender bem o seu hóspede: 1) a maturidade e o exercício pleno; 2) uma sábia ponderação e a coordenação da obra exterior para dentro do que o amor ordenasse; e 3) a "suma dignidade do hóspede querido".

Sem explicitar o porquê de cada consideração, nem ainda pesar uma compreensão em relação à outra, Eckhart segue ao próximo parágrafo direto para o tema da "satisfação racional" e da "satisfação sensível", por meio de uma citação de Tomás de Aquino, em que Deus está à disposição de todo homem para sua satisfação racional e sensível, ao máximo que esse desejar (AQUINO, 2006, v. 1, p. 546). Em sua análise, Eckhart parece estar de acordo que um homem está na satisfação racional, "quando nem amor nem dor, próprios da criatura, 
conseguem atrair para baixo o topo mais elevado da alma”, e assim indicar esta satisfação como mais próxima à perfeição do homem, uma vez já entendido que esta consiste em unir-se ao criador e não à criatura (ECKHART, 2008, p. 126).

Poderíamos assim pensar que a associação entre o racional e o sensível se revela na parábola, na qual cada uma das personagens representaria uma das atitudes. Em uma leitura óbvia, imputaríamos racionalidade à Maria, por ser a contemplativa, na doçura do manto de Jesus, e, a sensibilidade, à Marta, por ser ativa nas ocupações de servir. No entanto, os termos que Eckhart utiliza para caracterizar a "satisfação sensível" estão nos motivos enumerados em relação à Maria: "Satisfazer à natureza sensível significa que Deus nos dá consolo, contentamento e satisfação e assim somos mimados interiormente" (ECKHART, 2008, p. 126). Quem está no mimo do consolo e da interioridade é Maria, e por isto estaria nos prazeres da contemplação. Marta, ao contrário, está no conhecimento da vida.

Então Marta diz: "Senhor, ordena que me ajude!". Marta não disse isso por ódio; disse-o antes por um bem-querer amoroso, pelo qual foi impelida. Nós devemos chamá-lo então de um bem-querer amoroso ou de uma repreensão amorosa [...]. Ela percebeu que Maria estava tomada de prazer por toda sua satisfação de alma. Marta conhecia Maria melhor do que Maria conhecia Marta, pois vivera mais e vivera bem; e a vida concede o mais nobre conhecimento. A vida conhece melhor que o prazer ou que a luz tudo que podemos alcançar nessa vida abaixo de Deus e, de certo modo, conhece a vida de maneira mais límpida do que a luz eterna poderia conceder (ECKHART, 2008, p. 127).

A questão de Eckhart não está em conceber uma distinção entre 
satisfação sensível e satisfação racional, mas, sim, em sua identificação necessária à atividade e à contemplação, respectivamente. $\mathrm{O}$ modo mesmo da contemplação pode, pois, ser um "prazer" para a alma, mais do que uma atividade bem vivida pode sê-lo, e não implicar em um caminho reto de crescimento. Assim, a distinção aí se estabelece também entre "vida" e "prazer", para além de ação e contemplação. Pode-se, assim, ser contemplativo por prazer em vez de santidade e também ser ativo por superação do eu ensimesmado e união com o divino. Este é o paralelo entre Maria e Marta.

É claro que, para Eckhart, o fazer não indica necessariamente a santidade, mas o ser que sustenta este afazer. Basta remontar à máxima de Eckhart nas Conversações Espirituais:

Não se pense em fundamentar a santidade num fazer; antes se deve fundamentar a santidade num ser, pois as obras não nos santificam, nós é que santificamos as obras (ECKHART, 1999, p. 104).

O ser é o modo do fazer. O afazer de Marta já está per-feito no ser mesmo que ela é, em relação a toda e qualquer obra. Neste sentido, o seu afazer é vida e não mera utilização de obras; é um transbordamento do ser mesmo que ela já é.

Eckhart, na sequência do sermão, compara santos como São Paulo, em seu primeiro arrebatamento, a mestres da vida, que exercitaram a sua união com Deus em obras. Neste paralelo, mostra que a ausência de um exercício deixa o arrebatamento aquém, pois este se encontra em um estágio de satisfação consigo em relação a Deus, enquanto a ação é uma relação à vida em Deus sem a ideia contemplativa de "Deus". "Os mestres pagãos, pelo exercício das virtudes”, expressa Eckhart: 
Alcançaram um conhecimento tão elevado que conheceram cada uma das virtudes, por imagens, de modo muito mais preciso do que Paulo ou qualquer santo em seu primeiro arrebatamento (ECKHART, 2008, p. 128).

Eckhart lembra que se um homem estiver em arrebatamento, e alguém ao lado estiver necessitado de um prato de sopa, é muito mais santo sair do estado de graça e servir-lhe assim o prato (cf. ECKHART, 2006, p. 105).

É o que Marta pede que Jesus ordene à sua irmã, para que ela cresça nas execuções das obras. No entanto, Cristo também lhe faz uma repreensão amorosa, pedindo-a que tenha calma, pois a irmã Maria ainda seria como ela desejava, e se esta havia escolhida "a melhor parte", isto é, a que lhe dava mais prazer, também se tornaria perfeita. Nessa fala, repete o nome de Marta: "Marta, Marta, tu te ocupas com muitas coisas..." e, para Eckhart, a repetição do nome indica a perfeição:

Na primeira vez que disse Marta, demonstra sua perfeição nas obras temporais. Quando pronunciou pela segunda vez, demonstrou tudo que pertence à bem-aventurança eterna (ECKHART, 2009, p. 129).

O nome é repetido, pois demonstra que a irmã mais velha pertence tanto ao tempo quanto à eternidade, e, por esta razão, seria completa:

Sem impedimentos estão os que executam ordenadamente todas as suas obras seguindo a imagem da luz eterna; e essas pessoas estão junto às coisas e não nas coisas. Estão bem próximas e não possuem menos do que se estivessem lá em cima, no "círculo da eternidade". Digo "bem próximas", pois 
todas as criaturas "medeiam". Há dois tipos de "meio". Um é aquele sem o qual não posso chegar a Deus: é a obra e o empreendimento no tempo e esse não diminui a bem-aventurança eterna. Obra é quando nos exercitamos, a partir do exterior, nas obras das virtudes. Mas empreendimento é quando nos exercitamos, a partir do interior, com discernimento racional. O outro meio é este: ser liberto desse mesmo, a saber, do primeiro meio. Pois nós fomos colocados no tempo para que, pelo empreendimento intelectivo temporal, nos aproximemos de Deus e nos tornemos mais iguais a ele (ECKHART, 2008, p. 128-129).

Neste trecho, Eckhart aponta que o empreendimento da alma, ao modo de Marta, é superar o tempo dentro do tempo, de estar nas coisas sem ser impedida por nenhuma delas, tampouco sem livrar-se delas. É o que remetemos ao desprendimento e ao deixar-ser. O movimento de desprender-se está completo, assim, em seu caráter ativo (cf. SCHURMANN, 200o, p. 36): não se trata de abandonar as coisas, em um movimento de total desapego material, pois isto revelaria, sem dúvida, um apego, mas estar desprendido entre todas elas a ponto de nenhuma indicar impedimento para a correspondência com a luz eterna. Esta luz é íntima e está junta em todos os afazeres, realizando-os na mesma correspondência com a eternidade do Uno. Assim, Jesus diz a Marta: "Uma coisa só é necessária”. Uma: a total unidade entre todas as coisas no seio do Uno da criação. Quem está nesse modo, está "salvo" no tempo e na eternidade e tem o "seu discernimento racional" aberto para a Unidade.

Virgem é Marta, mas não apenas virgem. Eckhart cita a passagem do Evangelho de Lucas no início do Sermão 2, cujo versículo é o início da parábola de Marta e Maria: Intravit Jesus in quoddam castellum et 
mulier quaedam, Martha nomine, excepit illum in domun suam (BÍBLIA, 1982, Lc 10,38). A tradução do próprio Eckhart, porém, não é literal, conforme se vê no primeiro parágrafo. Ele diz: "Nosso Senhor Jesus Cristo subiu a um burgo e foi recebido por uma virgem que era mulher". O nome de "Marta", no caso, tornou-se "uma virgem que era mulher". Não é sem razão, e se acrescentamos as palavras colocadas no Sermão 86, compreendemos melhor a imagem de Marta: é o símbolo da perfeição da criatura humana. A um só passo é recepção intelectiva, no fundo da alma, e, é do tempo e da obra, que frutifica Deus em todas as coisas.

O significado da simbologia da mulher está expresso no próprio Sermão 2:

Agora prestai atenção e observai com precisão! Se o homem permanecesse para sempre moça-virgem, dele não viria nenhum fruto. Para tornar-se fecundo, é necessário que seja mulher. "Mulher" é o nome, o mais nobre que se pode atribuir à alma, e é muito mais nobre do que "moça-virgem". Que o homem conceba Deus em si é bom, e, nessa concepção, é ele moça-virgem. Mas que Deus se torne nele fecundo, isso é bem melhor. Pois frutificar a dádiva é a única gratidão para com a dádiva. E ali, o espírito é mulher, na gratidão que gera novamente, lá onde o espírito gera novamente Jesus para dentro do coração paterno de Deus (ECKHART, 2006, p. 48).

Receber Deus é, acima de tudo, gerá-lo. Nesse sentido, fala-se que a doutrina do desprendimento não é a do quietismo, nem da ataraxia estóica. Ser desprendido, em Eckhart, não é ser afastado, tampouco indiferente, isento de paixões (cf. SCHURMANN, 200o, p. 21). Eckhart chega a frisar, noutro momento, que "jamais um santo foi tão grandioso que não pudesse se comover" (ECKHART, 2009, p. 132). 
Estar em recepção divina não é estar fora dos afetos ou estar passivo diante de todos os acontecimentos: é estar na atividade da geração, é pertencer à própria dinâmica de criação divina. Ao acolher a deidade, o homem desprendido frutifica esta mesma deidade em todas as coisas. Virgem, assim, é a "mãe de Jesus": para que cada homem engendre Deus do fundo da alma, precisa torná-lo Filho entre os homens.

No Sermão 101, Eckhart distingue, em três pontos, o que consiste este nascimento e este eterno gerar: o lugar do nascimento, a atitude da virgem-mulher e os frutos que são gerados. A imagem do nascimento é utilizada a partir de uma citação de Agostinho: "Que este nascimento se produza sempre', diz Santo Agostinho, 'para quê isto me serve se não se produz em mim?' Que ele se produz em mim, é o que importa" (AGOSTINHO apud ECKHART, 2008, p. 191). Desse modo, o nascimento, ou, em termos teológicos, o Natal, não seria apenas um evento passado, isto é, uma data especial de calendário, referido a um acontecimento. Ele seria um ato permanente da alma, e, por ser permanente, é da ordem do sempre, do atual. O nascimento "sem descanso", em Eckhart, é um engendramento contínuo e um evento constante, pois acontece na eternidade (cf. SANTOS, 2012, p. 129).

No segundo ponto, retrata-se que o nascimento do Filho na deidade só interessa a cada homem na medida em que se produz no próprio homem: $\mathrm{O}$ mesmo filho que é gerado na eternidade há de ser gerado em cada homem. "É assim que Deus Pai engendra seu Filho: na unidade verdadeira da natureza divina [...]. Deus engendra seu Filho em nós exatamente da mesma maneira que ele faz no eterno" (ECKHART, 2008, p. 194). O que serve ao homem é que a geração 
eterna se dê também nele. A gratidão para este gerar é se tornar, ele mesmo, gerado e gerador, desde o qual todas as coisas ganham a união com o Filho. Gerar é receber a deidade e devolvê-la para o mundo, permanentemente.

Muitas boas dádivas são concebidas na virgindade, mas se não geradas em Deus novamente, com louvor de gratidão, na fecundidade da mulher, se estragam e se reduzem a nada. Com elas o homem jamais se torna bem-aventurado nem melhor. Ademais, sua virgindade não lhe serve para nada, pois ele, além da sua virgindade não é mulher, cheia de fecundidade. É nisso que está a perda (ECKHART, 2006, p. 50).

A virgindade de Marta aponta o seu acolhimento na unidade de Deus pela recepção. Maria, a irmã de Marta, ainda não é virgem, como traz o seu nome: "era Maria no nome, mas não ainda no ser" (ECKHART, 2008, p. 130). Ela não era ainda mãe, como é próprio do ser de Maria. Estava ainda acomodada "pelo prazer e pela doçura e havia recém-ingressado na escola e aprendia a viver". (Ibidem). Não estava solta e livre como é próprio da virgindade, tampouco estava apta a frutificá-la, como é próprio da mulher. Para Eckhart, o recolhimento nesta interioridade será sempre improdutivo, no sentido filial do termo. É a potência de toda alma sem a atualização em Deus, uma semente nunca germinada, uma árvore que não deu frutos. É preciso que o ser virgem deixe ser este ser mulher para que se engendre.

A interioridade, assim, é ela mesma uma exterioridade: Deus é no ser e para além do ser. Deus está no homem, que o segue a fim de aperfeiçoar-se. É na interioridade e, para além dela, exteriorizando-se, tornando-se carne a partir do verbo, vinculando-se ao tempo pela força da eternidade. A deidade precisa emergir em cada obra, em cada 
imagem ou então de nada adiantará.

Quem totalmente, por um instante, deixasse a si mesmo, a ele tudo seria dado. Se, ao contrário, um homem tivesse deixado por vinte anos a si mesmo e, mesmo que um só instante se retomasse, este jamais teria deixado a si mesmo (ECKHART, 2006, p. 105).

Na frutificação, nem "antes", nem "depois"; não há planejamento para se engendrar, nem lembranças de engendramentos. Só se frutifica agora mesmo, sempre, a tal ponto que nada é prévio nem posterior ao nascimento de Deus. O nascimento permeia tudo e esta é a nobreza do homem desprendido, e o fruto da mulher virgem, ambos, uma única dimensão.

Sendo assim, a vida ativa em Marta expressa o transbordamento interior da divindade na obra externa do seu afazer. O modo de Deus se dar, aqui e agora, no mundo dos homens, se efetiva por meio da ação fecunda dos homens unidos a Deus, enquanto "mulher", enquanto aquela que engendra o Uno inteira e reiteradamente. Este é o caráter desprendido, que liga humanidade e deidade, capaz de tornar ativo o homem, sem deixar o primado ontológico da criação.

Marta é pobre inteiramente e, uma vez saída do modo da criatura, se mantém una com Deus. Eckhart indica que Marta não vive para contemplar a divindade, mas para vivê-la: já a possui no seio de seu coração de mulher e ninguém mais pode tirá-lo, nem mesmo Deus, pois aí só a deidade entra. Desse modo, é que Eckhart responde a uma questão no tratado Do desprendimento: ora, se é o desprendimento a virtude mais alta, por que nas Escrituras está dito que Jesus, ante a sua mãe Maria, teria olhado a humildade de sua serva e não o desprendimento (Lc 1,48)? É que o desprendimento é a interioridade imóvel que, contudo, move e deixa mover todas as obras. 
O seu essencial se perfaz, não é nenhum ser, mas por toda ultrapassagem de ser. Por isso, Jesus não poderia olhar o desprendimento tão somente, mas, sim, apenas os seres das virtudes:

E porque Nosso Senhor, quando quis fazer-se homem, permaneceu imóvel em seu desprendimento, Nossa Senhora bem sabia que Ele desejava dela a mesma coisa (ECKHART, 1991, p. 150).

Se pelo contrário, Jesus tivesse mencionado o desprendimento, este se teria turvado, deixando de "ser total e perfeito". Em todas as ações do homem desprendido reside o desprendimento, sem que este seja definido em qualquer instante, sem que o desprendimento mesmo se torne um dos seres com quem se relaciona.

A atitude participativa da vida, que não abandona a relação com o sagrado, é uma disposição milenar, que pode ser encontrada em outras narrativas, como uma das próprias referentes ao pensador originário Heráclito de Éfeso, pensador do Logos, aqui referido. Contase que ele estava em sua cabana, junto ao forno, aquecendo-se contra o frio, quando chegaram visitantes de longe para escutarem suas palavras. Ao verem o eminente pensador em uma atitude prosaica, chegaram a recuar e querer sair, mas Heráclito os interceptou: "Entrem. Aqui também habitam os Deuses". Se na narrativa do Evangelho, a visita é ilustre, e as anfitriãs se põem a recebê-la de modo diverso, nesta as visitas querem deliciar-se com o que ouvem do anfitrião, este, contudo, não lhe traz doçura alguma, não consola, apenas é cotidianamente.

Segundo Heidegger, lido por Carneiro Leão (Cf. LEÃO, 1997, p. 16), os visitantes ficam decepcionados por um homem extraordinário, de onde se ouviam grandes histórias e enigmas correrem por Éfeso, 
ocupar-se de algo tão ordinário, que é aquecer-se do frio, em uma cabana tão simples. Diante do quadro, perdem a vontade de entrar. $\mathrm{O}$ que poderiam, afinal, aprender com um homem e o seu forno? Não já viram inúmeras cenas assim, já não conhecem tudo sobre o homem com frio e o forno? Precisariam vir de tão longe para ver o banal? Não haveria ali nada a contemplar, a aumentar as graças do pensamento e do entendimento da realidade. Assim, é possível que supusessem ser necessário a um pensador ter modos estranhos e viver em situações curiosidades, em um isto, ou em um aquilo referencial. Quer dizer: estar num outro mundo e emigrar para um infinito invisível, nunca presente, sempre transcendental. Heráclito, porém, os corrige e responde: "Entrem, aqui também habitam os Deuses". Convidaria aí para entrar na casa, esta morada do homem, a fim de verem eles também o extraordinário em todas as coisas. Estar sim entre as coisas, pois para quem se dispõe, ali também se revela o sagrado.

É dessa maneira, pois, que Heidegger situa a questão do extraordinário e do ordinário na visão do Heráclito agachado à fogueira:

Não é preciso evitar o conhecido e o ordinário e perseguir o extravagante, o excitante e o estimulante na esperança ilusória de, assim, encontrar o extraordinário. Vocês devem simplesmente permanecer em seu cotidiano e ordinário, como eu aqui, que me abrigo e aqueço junto ao forno. Não será isso que faço, e esse lugar em que me aconchego, já suficientemente rico em sinais? O forno presenteia o pão. Como pode o homem viver sem a dádiva do pão? Essa dádiva do forno é o sinal indicador do que são os theoí, os deuses. São os daíontes, os que se oferecem como extraordinário na intimidade do ordinário (HEIDEGGER, 1998, p. 24). 
Marta compreende que o sagrado já habita e aquece a casa no fogo originário. Com isso, no ato de cuidar e de cuidar-se a deidade mesma transborda. Eis a atitude mística para a recepção do ser divino no sentido de vir tornar-se o advérbio do Verbo. Se Jesus está em viagem e é um hóspede, significa que o ser da deidade é movimento; é, portanto, verbal. O seu acolhimento se dá no movimento contínuo de uma realidade que não se estanca, nem na alma mesma de quem tenta apreendê-la. Assim, em O Homem Nobre, Eckhart diz que o homem pleno é aquele que parte para uma terra distante e regressa. Eis o ciclo da alma perfazendo em si mesmo, desprendendo-se e retornando. $\mathrm{O}$ homem retorna porque é desprendido.

\section{Referências bibliográficas}

AGOSTINHO. De magistro. São Paulo: Nova Cultural, 1987 (Col. Os Pensadores).

. Comentarios de San Agustín a las lecturas litúrgicas. Valladolid: Estudio Agustiniano, 1986.

AQUINO, Tomás. Suma Teológica - Vol. VII. São Paulo: Loyola, 2006.

BIBLIA. Português. Bíblia sagrada. Tradução: Centro Bíblico Católico. 34. ed rev. São Paulo: Ave Maria, 1982.

ECKHART, Mestre. O livro da divina consolação e outros textos seletos. Petrópolis, RJ: Vozes, 1991.

. Sermões alemães vol. 1. Trad. GIACHINI, Enio Paulo. Petrópolis, RJ: Vozes, 2006.

. Sermões alemães vol. 2. Trad. GIACHINI, Enio Paulo. Petrópolis, RJ: Vozes, 2009.

HEIDEGGER, Heráclito. Rio de Janeiro: Relume Dumará, 1998. 
JARCZYK, G.; LABARRIÈRE, P.-J. Maître Eckhart ou l'empreinte du desert. Paris: Albin Michel, 1995.

LEÃO, Emmanuel Carneiro. Heráclito e A Aprendizagem do

Pensamento. Revista de Filosofia Antiga - Kleos, Rio de Janeiro - IFCS UFRJ, v. 1, nº 1, p. 113-142, 1997.

SANTOS, Bento Silva. O Gottesgeburtszyklus de Meister Eckhart: a mística fundamental do "nascimento de Deus na alma" (Sermões 101 a 104). In: Mística e Milenarismo na Idade Média. Jan-Jun 2012.

SCHÜRMANN, Reiner. Wandering Joy: Meister Eckhart's mystical philosophy. Lindisfarne Books, 2001.

TANQUEREY, A. Compêndio da teologia ascética e mística. Porto:

Livraria Apostolado da Imprensa, 1955. 